Research Paper

\title{
Survival Outcomes for Patients with Surgical and Non-Surgical Treatments in Stages I-III Small-Cell Lung Cancer
}

\author{
Keying Che1, Hongchang Shen³, Xiao Qu¹, Zhaofei Pang1, Yuanzhu Jiang2, Shaorui Liu1, Xudong Yang1, \\ Jiajun $\mathrm{Du}^{1,2, \bigotimes}$ \\ 1. Institute of Oncology, Shandong Provincial Hospital Affiliated to Shandong University, 324 Jingwu Road, Jinan, 250021, P.R. China \\ 2. Department of Thoracic Surgery, Shandong Provincial Hospital Affiliated to Shandong University, 324 Jingwu Road, Jinan, 250021, P.R. China \\ 3. Department of Oncology, Shandong Provincial Hospital Affiliated to Shandong University, 324 Jingwu Road, Jinan, 250021, P.R. China \\ $\square$ Corresponding author: Jiajun Du, 324 Jingwu Road, Jinan, 250021 P.R. China; Fax: +86-0531-68777100; E-mail: dujiajun@sdu.edu.cn \\ (c) Ivyspring International Publisher. This is an open access article distributed under the terms of the Creative Commons Attribution (CC BY-NC) license \\ (https://creativecommons.org/licenses/by-nc/4.0/). See http://ivyspring.com/terms for full terms and conditions.
}

Received: 2017.10.30; Accepted: 2018.01.21; Published: 2018.04.06

\begin{abstract}
Objectives: Chemotherapy and radiation therapy are the standard treatments for patients with small-cell lung cancer (SCLC). However, recent studies suggest that patients with limited stage (I-III) SCLC may benefit from surgical treatment. This study was performed to evaluate the survival outcomes of surgery for stage I-III SCLC.

Methods: This analysis used data from the Surveillance, Epidemiology, and End Results (SEER) database. All stage I-III (excluding N3 and Nx) SCLC patients received a diagnosis between 2004 and 2014. Overall survival (OS) and lung cancer-specific survival (LCSS) were determined by Kaplan-Meier analysis and compared using the log-rank test. A Cox proportional hazard model identified relevant survival variables.

Results: A total of 4,780 histologically confirmed patients were identified from the SEER database, comprising 1,018 patients (21.3\%) with stage I disease; 295 (6.2\%) with stage II; and 3,467 (72.5\%) with stage III disease. Among all of the patients, 520 had been treated with surgery, the majority ( $\mathrm{n}$ $=344 ; 66.2 \%$ ) of whom had stage I disease. The hazard ratio (HR) for OS and LCSS, in patients who underwent surgery, according to stage were as follows: OS, 0.369 and LCSS, 0.335 in stage I; OS, 0.549 and LCSS, 0.506 in stage II; and OS, 0.477 and LCSS, 0.456 in stage III (all $p<0.001$ ). Patients who underwent surgery had significantly better OS, and lobectomy was associated with the best outcome.

Conclusions: Surgical resection was associated with significantly improved OS outcomes and should be considered in the management of stage I-III SCLC.
\end{abstract}

Key words: Small-cell lung cancer; surgical resection; lobectomy; postoperative radiation therapy; SEER

\section{Introduction}

Lung cancer is the leading cause of cancer-related death worldwide. In the United States, it is the second most common cancer (approximately $13 \%)$ and was the leading cause of cancer-related death for both sexes (approximately 26\%) in 2016 [1]. Small-cell lung cancer (SCLC), which accounts for approximately $15 \%$ of all lung cancer cases, has a poor prognosis because of its very aggressive clinical course and early metastasis. The primary cause of SCLC is smoking; $90 \%$ of SCLC patients are current or previous smokers, with an increased risk of disease positively correlated with smoking duration $[2,3]$. SCLC is generally staged on a binary two-stage classification based on the Veterans Administration Lung Study Group system: limited disease (LD) wherein the disease is confined to the ipsilateral 
hemothorax and occurrence of regional lymph node metastasis, and extensive disease (ED) wherein the disease has progressed beyond the ipsilateral hemothorax [4, 5]. A tumor-node-metastasis (TNM) staging system for SCLC was also recently adopted [6].

Currently, the standard treatment for SCLC patients is chemotherapy and radiotherapy. However, before the 1970s, surgical resection was a common treatment for early-stage SCLC [7-9]. In 1973, the Medical Research Council reported that radiotherapy led to higher survival compared with surgical resection [10]. In addition, one study enrolled 328 patients with limited-stage SCLC in a trial to evaluate the effects of surgical treatment in patients responding to chemotherapy. Those results did not support pulmonary resection [11]. Based on those pivotal findings, chemotherapy and radiotherapy were recommended as appropriate therapies for SCLC, and the use of surgical resection was essentially discontinued.

An increasing amount of research supports the fact that surgical resection can improve survival outcomes in patients with SCLC, especially in early-stage patients [12-26]. Furthermore, the European Society for Medical Oncology recently recommended that surgery be considered in select cases in T1-2, N0-1 stage without mediastinal node involvement, which should be followed by chemotherapy; while surgery for pathologic N1 and unforeseen N2 cases should be followed by postoperative radiotherapy (PORT) [27]. In addition, surgical resection of small lesions without lymph node involvement has been recommended as a curative choice for LD-SCLC [28]. Therefore, to further define the role of surgery in patients with SCLC, we acquired data from the Surveillance, Epidemiology, and End Results (SEER) database and performed a retrospective analysis of patients with stage I-III SCLC diagnosed from 2004 to 2014 . We also evaluated the outcomes of PORT versus surgery alone treatment in patients with SCLC.

\section{Materials and Methods}

\section{Data Source and Ethics statement}

The SEER database is sponsored by the National Cancer Institute $(\mathrm{NCI})$, and provides registry information on cancer incidence, staging, and patient survival in specific geographies within the United States since 1973. We accessed the database from the SEER website (http://seer.cancer.gov/data/options .html). The study cohort was comprised of de-identified individual patients from the NCI SEER 18 Registries (SEER ${ }^{*}$ Stat Database: Incidence-SEER
18 Custom Data [with additional treatment fields] Nov 2016 Sub). SEER data are de-identified (i.e., without personal identifiers) and submitted electronically to the NCI; they are available to the public for research purposes. The use of de-identified subject data precluded Institutional Review Board and ethics committee approvals.

\section{Patient selection}

Data from 4,780 patients who had been diagnosed with histologically confirmed SCLC from 2004 to 2014 were extracted from the SEER database. Patients who met the following criteria were eligible for inclusion in the study: (1) Site and morphology. Site recoded ICD-O-3/WHO 2008: Lung and Bronchus. (2) International Classification of Diseases for Oncology, $3^{\text {rd }}$ Edition (ICD-03) codes 8002, 8041, 8042, 8043, 8044, and 8045. (3) Without chemotherapy (Chemotherapy recode: No/Unknown). (4) Patients with American Joint Committee on Cancer (AJCC) stage I, II, or III disease. Patients treated without surgery were staged clinically and patients who underwent surgery were staged pathologically. Patients with N3 and Nx disease, surgery unknown, and survival months unknown were excluded from the study. Demographic data collected included patients age at diagnosis, gender, and race. Pathologic characteristics collected included primary tumor site and neoplastic grade.

\section{Staging}

All patients were staged using AJCC with stage I, II, or III disease. Patients who underwent surgery were staged pathologically and those without surgery had clinic staging. Patients with N3 SCLC were excluded from the study as they typically do not undergo surgery due to the potential involvement of contralateral mediastinal, contralateral hilar, ipsilateral or contralateral scalene, or supraclavicular lymph nodes. Patients with $\mathrm{Nx}$ disease were also excluded as their regional lymph node status could not be assessed. Therefore patients with stage I-III, N0-N2 SCLC were included in this study.

\section{Outcomes}

The primary outcomes of this study were overall survival (OS) and lung cancer-specific survival (LCSS). Follow-up duration was calculated from 2004 to 2014.

\section{Statistical Analysis}

All data were analyzed using the SPSS software package, version 20.0 (IBM, SPSS Statistics, Chicago, IL, USA). The Pearson's chi-squared test and Fisher's exact probability tests were used to analyze differences between qualitative data of surgery and 
no-surgery groups. The Kaplan-Meier method was used to estimate overall survival (OS) and lung cancer-specific survival (LCSS). The proportional hazards model was used to estimate OS and LCSS hazard ratios for prognostic factors including age, gender, race, and neoplastic grade. A $P$ value $<0.05$ was considered statistically significant.

\section{Results}

\section{Baseline demographic characteristics}

We identified 4,780 patients diagnosed from 2004 to 2014 with stages I to III SCLC, excluding N3 and Nx patients. The baseline characteristics of all subjects identified through the SEER database are shown in Table 1 . The median age was 74 years (range: 29-101 years), of which $22.2 \%$ were age $<65$ and $77.8 \%$ were age $\geq 65$. The female proportion was slightly greater $(54.2 \%)$ than the male population $(45.8 \%)$. The majority of patients $(86.5 \%)$ were white, $9.3 \%$ were black, and $4.2 \%$ were other. At diagnosis, 1,018 patients $(21.3 \%)$ had stage I disease; 295 (6.2\%) had stage II, and 3,467 (72.5\%) had stage III disease. Of the total 4,780 patients, 4,260 (89.0\%) did not undergo surgical treatment, whereas 520 patients $(11.0 \%)$ underwent surgery. While a higher number of nodes were examined in the surgery group (mean 6.36 compared to 0.16 in the non-surgery group; $p<0.001$ ), more positive nodes were identified in the non-surgery group (mean 1.16 vs. 0.68 in the surgery group; $p<0.001$ ). Regardless of the location of the primary tumor site (main bronchus; upper, middle, or lower lobe; overlapping lung lesion; or lung 'not otherwise specified') an overwhelming majority ( $>85 \%$ for each site; $p<0.001$ ) were not treated with surgery. Table 1 summarizes the baseline characteristics and key prognostic factors of patients in the surgery and no-surgery groups including age, primary tumor site, radiation sequence with surgery, TNM stage, tumor grade, and number of nodes examined and positive.

\section{Features of surgically treated patients}

Of the 520 patients treated with surgery, 344 $(66.2 \%)$ had stage I disease, 60 (11.5\%) had stage II, and $116(22.3 \%)$ had stage III disease. Surgical treatments were as follows: 299 patients $(6.5 \%)$ underwent lobectomy representing $57.5 \%$ of surgical treatment; 194 patients (4.0\%) underwent partial/wedge/segmental resection representing $37.3 \%$ of surgical treatment; 20 patients $(0.4 \%)$ underwent pneumonectomy representing 3.9\% of surgical treatment; and surgery type was unknown for 7 patients $(0.1 \%)$ representing $1.3 \%$ of surgical treatment.
Table 1. Characteristics of Patients With Stage I to III Small Cell Lung Cancer $(n=4,780)$

\begin{tabular}{|c|c|c|c|c|}
\hline Characteristics & No. (\%) & $\begin{array}{l}\text { No } \\
\text { surgery }(n=4,260) \\
\text { No. }(\%)\end{array}$ & $\begin{array}{l}\text { Surgery }(n=520) \\
\text { No. }(\%)\end{array}$ & $\begin{array}{l}\mathrm{P} \\
\text { Value }\end{array}$ \\
\hline Age(years) & & & & 0.001 \\
\hline$<65$ & $1062(22.2)$ & $917(86.3)$ & $145(13.7)$ & \\
\hline$\geq 65$ & $3718(77.8)$ & $3343(89.9)$ & $375(10.1)$ & \\
\hline Gender & & & & 0.451 \\
\hline Female & $2593(54.2)$ & $2319(89.4)$ & $274(10.6)$ & \\
\hline Male & $2187(45.8)$ & $1941(88.8)$ & $246(11.2)$ & \\
\hline Race & & & & 0.233 \\
\hline White & $4133(86.5)$ & $3671(88.8)$ & $462(11.2)$ & \\
\hline Black & $447(9.3)$ & $408(91.3)$ & $39(8.7)$ & \\
\hline Other & $200(4.2)$ & $181(90.5)$ & 19(9.5) & \\
\hline Primary site & & & & $\begin{array}{l}< \\
0.001\end{array}$ \\
\hline Main bronchus & $502(10.5)$ & $488(97.2)$ & $14(2.8)$ & \\
\hline Upper lobe & $2242(46.9)$ & $1930(86.1)$ & $312(13.9)$ & \\
\hline Middle lobe & $238(5.0)$ & $208(87.4)$ & $30(12.6)$ & \\
\hline Lower lobe & $1076(22.5)$ & $934(86.8)$ & $142(13.2)$ & \\
\hline Overlapping lesion of lung & $69(1.4)$ & $60(87.0)$ & $9(13.0)$ & \\
\hline Lung, NOS & $653(13.7)$ & $640(98.0)$ & $13(2.0)$ & \\
\hline \multicolumn{5}{|l|}{ Surgery } \\
\hline No surgery & $4260(89.0)$ & - & - & \\
\hline Lobectomy & $299(6.5)$ & - & - & \\
\hline $\begin{array}{l}\text { Partial/wedge/segmental } \\
\text { resection }\end{array}$ & 194(4.0) & - & - & \\
\hline Pneumonectomy & $20(0.4)$ & - & - & \\
\hline Surgery, Nos & $7(0.1)$ & - & - & \\
\hline $\begin{array}{l}\text { Radiation sequence with } \\
\text { surgery }\end{array}$ & & & & $\begin{array}{l}< \\
0.001\end{array}$ \\
\hline No radiation & $4681(98.0)$ & $4195(89.6)$ & $486(10.4)$ & \\
\hline PORT & $92(1.9)$ & $62(67.4)$ & $30(32.6)$ & \\
\hline Others & $7(0.1)$ & $3(42.9)$ & $4(57.1)$ & \\
\hline TNM stage & & & & $\begin{array}{l}< \\
0.001\end{array}$ \\
\hline Stage I & 1018(21.3) & $674(66.2)$ & $344(33.8)$ & \\
\hline Stage II & $295(6.2)$ & 235(79.7) & $60(20.3)$ & \\
\hline Stage III & $3467(72.5)$ & $3351(96.7)$ & $116(3.3)$ & \\
\hline Grade & & & & $\begin{array}{l}< \\
0.001\end{array}$ \\
\hline Well differentiated; Grade I & $15(0.3)$ & $8(53.3)$ & $7(46.7)$ & \\
\hline $\begin{array}{l}\text { Moderately differentiated; } \\
\text { Grade II }\end{array}$ & $43(0.9)$ & $19(44.2)$ & $24(55.8)$ & \\
\hline $\begin{array}{l}\text { Poorly differentiated; } \\
\text { Grade III }\end{array}$ & $598(12.5)$ & $421(70.4)$ & $177(29.6)$ & \\
\hline $\begin{array}{l}\text { Undifferentiated; } \\
\text { anaplastic; Grade IV }\end{array}$ & 1097(23.0) & $945(86.1)$ & 152(13.9) & \\
\hline Unknown & $3027(63.3)$ & $2867(94.7)$ & $160(5.3)$ & \\
\hline No. of nodes examined & & & & $\begin{array}{l}< \\
0.001\end{array}$ \\
\hline Mean & 0.84 & 0.16 & 6.36 & \\
\hline $\mathrm{SD}$ & 3.496 & 1.676 & 7.341 & \\
\hline No. of nodes positive & & & & $\begin{array}{l}< \\
0.001\end{array}$ \\
\hline Mean & 0.87 & 1.16 & 0.68 & \\
\hline $\mathrm{SD}$ & 1.559 & 1.362 & 1.652 & \\
\hline Year of diagnosis & & & & 0.138 \\
\hline 2004 & $481(10.0)$ & $431(89.6)$ & $50(10.4)$ & \\
\hline 2005 & $429(9.0)$ & $376(87.6)$ & $53(12.4)$ & \\
\hline 2006 & $427(8.9)$ & $378(88.5)$ & $49(11.5)$ & \\
\hline 2007 & $458(9.6)$ & 409(89.3) & 49(10.7) & \\
\hline 2008 & $434(9.1)$ & $387(89.2)$ & $47(10.8)$ & \\
\hline 2009 & $482(10.1)$ & 409(84.9) & $73(15.1)$ & \\
\hline 2010 & $428(8.9)$ & $387(90.4)$ & $41(9.6)$ & \\
\hline 2011 & $419(8.8)$ & $375(89.5)$ & $44(10.5)$ & \\
\hline 2012 & $397(8.3)$ & $364(91.7)$ & $33(8.3)$ & \\
\hline 2013 & $405(8.5)$ & $364(89.9)$ & $41(10.1)$ & \\
\hline 2014 & $420(8.8)$ & $380(90.5)$ & $40(9.5)$ & \\
\hline
\end{tabular}


Table 2. Univariate Analysis for Stage I Small Cell Lung Cancer Using Cox Proportional Hazards Model $(n=1,018)$

\begin{tabular}{|c|c|c|c|c|}
\hline & OS & & LCSS & \\
\hline Variable & HR & $P$ value & HR & $P$ value \\
\hline \multicolumn{5}{|l|}{ Age, years } \\
\hline \multicolumn{5}{|l|}{$<65$} \\
\hline$\geq 65$ & $1.348(1.118-1.625)$ & 0.002 & $1.262(1.017-1.565)$ & 0.034 \\
\hline \multicolumn{5}{|l|}{ Gender } \\
\hline \multicolumn{5}{|l|}{ Female } \\
\hline Male & $1.073(0.931-1.238)$ & 0.329 & $0.985(0.833-1.165)$ & 0.859 \\
\hline \multicolumn{5}{|l|}{ Race } \\
\hline \multicolumn{5}{|l|}{ White } \\
\hline Black & $0.879(0.691-1.118)$ & 0.293 & $0.927(0.703-1.223)$ & 0.592 \\
\hline Other & $0.830(0.557-1.238)$ & 0.361 & $0.827(0.516-1.324)$ & 0.428 \\
\hline \multicolumn{5}{|l|}{ Surgery } \\
\hline \multicolumn{5}{|l|}{ No } \\
\hline Yes & $0.369(0.312-0.435)$ & $<0.001$ & $0.335(0.275-0.409)$ & $<0.001$ \\
\hline \multicolumn{5}{|l|}{$\operatorname{PORT}(\mathrm{n}=342)$} \\
\hline \multicolumn{5}{|l|}{ Surgery alone } \\
\hline PORT & $0.790(0.294-2.127)$ & 0.641 & $0.907(0.289-2.849)$ & 0.867 \\
\hline \multicolumn{5}{|l|}{$\begin{array}{l}\text { Surgery type }(\mathrm{n}= \\
340)\end{array}$} \\
\hline \multicolumn{5}{|l|}{ Lobectomy } \\
\hline $\begin{array}{l}\text { Partial/wedge/se } \\
\text { gmental resection }\end{array}$ & $1.445(1.086-1.924)$ & 0.012 & $1.369(0.961-1.950)$ & 0.082 \\
\hline Pneumonectomy & $3.585(1.806-7.120)$ & $<0.001$ & $3.268(1.414-7.554)$ & 0.006 \\
\hline \multicolumn{5}{|l|}{ Grade $(\mathrm{n}=515)$} \\
\hline \multicolumn{5}{|l|}{ Grade I and II } \\
\hline Grade III and IV & 1.812 (1.113-2.949) & 0.017 & $1.711(0.980-2.987)$ & 0.059 \\
\hline
\end{tabular}

Table 3. Univariate Analysis for Stage II Small Cell Lung Cancer Using Cox Proportional Hazards Model $(\mathrm{n}=295)$

\begin{tabular}{lllll}
\hline & OS & \multicolumn{2}{l}{ LCSS } & \\
\hline Variable & HR & P value & HR & P value \\
\hline $\begin{array}{l}\text { Age, years } \\
<65\end{array}$ & & & & \\
$\geq 65$ & $1.413(1.064-1.876)$ & 0.017 & $1.532(1.114-2.108)$ & 0.009 \\
$\begin{array}{l}\text { Gender } \\
\text { Female }\end{array}$ & & & & \\
$\begin{array}{l}\text { Male } \\
\text { Race }\end{array}$ & $0.998(0.783-1.272)$ & 0.987 & $0.976(0.747-1.275)$ & 0.858 \\
$\begin{array}{l}\text { White } \\
\text { Black }\end{array}$ & $0.814(0.539-1.228)$ & 0.326 & $0.834(0.529-1.314)$ & 0.433 \\
$\begin{array}{l}\text { Other } \\
\text { Surgery }\end{array}$ & $1.017(0.602-1.718)$ & 0.949 & $1.046(0.595-1.839)$ & 0.875 \\
$\begin{array}{l}\text { No } \\
\text { Yes }\end{array}$ & $0.549(0.402-0.749)$ & $<0.001$ & $0.506(0.356-0.718)$ & $<0.001$ \\
$\begin{array}{l}\text { PORT(n=60) } \\
\text { Surgery alone }\end{array}$ & & & & \\
$\begin{array}{l}\text { PORT } \\
\text { Surgery type (n }=\end{array}$ & $1.015(0.361-2.849)$ & 0.978 & $1.204(0.424-3.417)$ & 0.728 \\
$\begin{array}{l}\text { 60) } \\
\text { Lobectomy }\end{array}$ & & & & \\
$\begin{array}{l}\text { Partial/wedge/se } \\
\text { gmental resection }\end{array}$ & $1.466(0.771-2.789)$ & 0.243 & $1.793(0.896-3.588)$ & 0.099 \\
$\begin{array}{l}\text { Pneumonectomy } \\
\text { Grade (n }=125)\end{array}$ & $2.706(1.025-7.149)$ & 0.045 & $2.115(0.621-7.205)$ & 0.231 \\
$\begin{array}{l}\text { Grade I and II } \\
\text { Grade III and IV }\end{array}$ & $6.660(1.620-27.372)$ & 0.009 & $4.975(1.212-20.429)$ & 0.026 \\
\hline & & & &
\end{tabular}

\section{Effects of surgery on OS and LCSS}

The results of the univariate Cox analysis of OS and LCSS are shown in Tables 2, 3, and 4 for each stage of disease. Survival analysis revealed that age and surgery versus no-surgery were all significant factors for OS and LCSS. Grade was a significant factor for survival for stage II patients. Surgery was associated with a higher OS and LCSS at each stage of SCLC with the following hazard ratios (HRs): 0.369 (OS) and 0.335 (LCSS) for stage I; 0.549 (OS) and 0.506 (LCSS) for stage II; and 0.477 (OS) and 0.456 (LCSS) for stage III (all $p<0.001$ at each stage). Fig. 1 shows the Kaplan-Meier survival analysis for OS and LCSS based on surgery or no-surgery (all $p<0.001$ ). For stage I-III patients, the cumulative OS rate was 1.3\% for no-surgery compared to $13.2 \%$ for surgery, and the LCSS rate was $4.1 \%$ for no-surgery compared to $27.6 \%$ for the surgery group. For stage I patients, the cumulative OS rate was $2.9 \%$ for no-surgery versus $21.0 \%$ for surgery, and the LCSS rate was $8.5 \%$ for no-surgery versus $43.2 \%$ for the surgery group. For stage II patients, the cumulative OS rate was $2.0 \%$ for no-surgery compared to $5.9 \%$ for surgery, and the LCSS rate was $5.5 \%$ for no-surgery compared to $20.4 \%$ for the surgery group. For stage III patients, the cumulative OS rate was $0.9 \%$ for no-surgery versus $5.1 \%$ for surgery, and the LCSS rate was $3.0 \%$ for no-surgery versus $8.0 \%$ for the surgery group.

Table 4. Univariate Analysis for Stage III Small Cell Lung Cancer Using Cox Proportional Hazards Model ( $n=3,467)$

\begin{tabular}{|c|c|c|c|c|}
\hline & OS & & LCSS & \\
\hline Variable & HR & P value & HR & $P$ value \\
\hline \multicolumn{5}{|l|}{ Age, years } \\
\hline \multicolumn{5}{|l|}{$<65$} \\
\hline$\geq 65$ & $1.416(1.302-1.540)$ & $<0.001$ & $1.384(1.265-1.514)$ & $<0.001$ \\
\hline \multicolumn{5}{|l|}{ Gender } \\
\hline \multicolumn{5}{|l|}{ Female } \\
\hline Male & $1.032(0.963-1.105)$ & 0.373 & $1.027(0.953-1.106)$ & 0.484 \\
\hline \multicolumn{5}{|l|}{ Race } \\
\hline \multicolumn{5}{|l|}{ White } \\
\hline Black & $0.962(0.852-1.085)$ & 0.528 & $0.904(0.791-1.033)$ & 0.139 \\
\hline Other & $0.946(0.795-1.127)$ & 0.536 & $0.918(0.759-1.110)$ & 0.379 \\
\hline \multicolumn{5}{|l|}{ Surgery } \\
\hline \multicolumn{5}{|l|}{ No } \\
\hline Yes & $0.477(0.389-0.585)$ & $<0.001$ & $0.456(0.365-0.570)$ & $<0.001$ \\
\hline \multicolumn{5}{|l|}{ PORT(n=116) } \\
\hline \multicolumn{5}{|l|}{ Surgery alone } \\
\hline PORT & $0.961(0.561-1.646)$ & 0.884 & $1.213(0.700-2.103)$ & 0.492 \\
\hline \multicolumn{5}{|l|}{$\begin{array}{l}\text { Surgery type }(\mathrm{n}= \\
113)\end{array}$} \\
\hline \multicolumn{5}{|l|}{ Lobectomy } \\
\hline $\begin{array}{l}\text { Partial/wedge/se } \\
\text { gmental resection }\end{array}$ & $1.419(0.928-2.169)$ & 0.106 & $1.391(0.872-2.220)$ & 0.167 \\
\hline Pneumonectomy & $2.262(0.878-5.825)$ & 0.091 & $2.109(0.735-6.049)$ & 0.165 \\
\hline \multicolumn{5}{|l|}{ Grade $(n=1,113)$} \\
\hline \multicolumn{5}{|l|}{ Grade I and II } \\
\hline Grade III and IV & $1.191(0.747-1.898)$ & 0.463 & $1.152(0.702-1.888)$ & 0.576 \\
\hline
\end{tabular}

\section{Effect of surgery type on survival}

Next, we examined the effect of surgery type on OS and LCSS. Comparing lobectomy, partial/ wedge/segmental resection, pneumonectomy, and no-surgery, four survival distributions showed that lobectomy was the most effective surgical method (Fig. 2). 
A

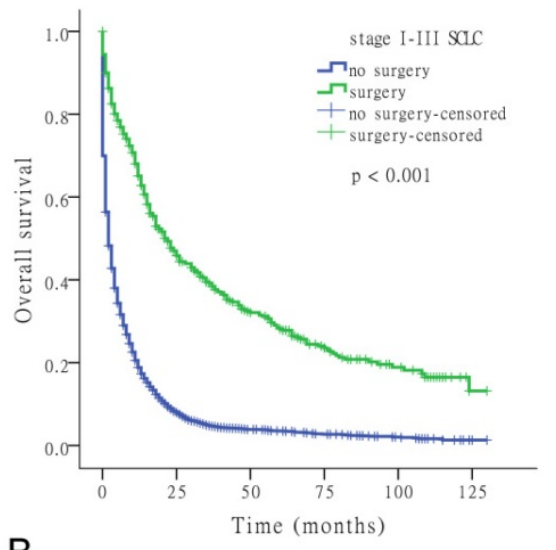

B

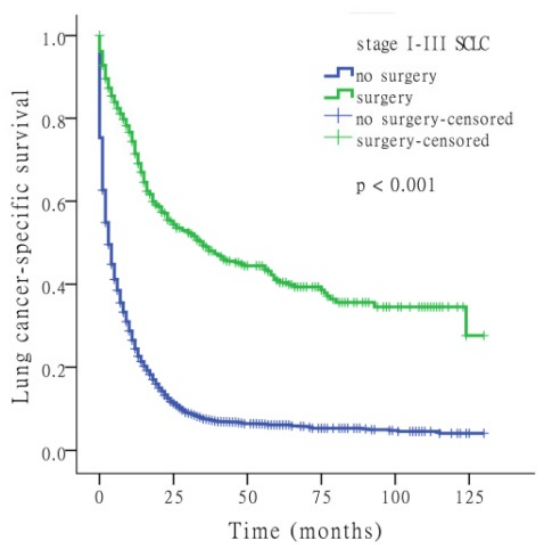

E

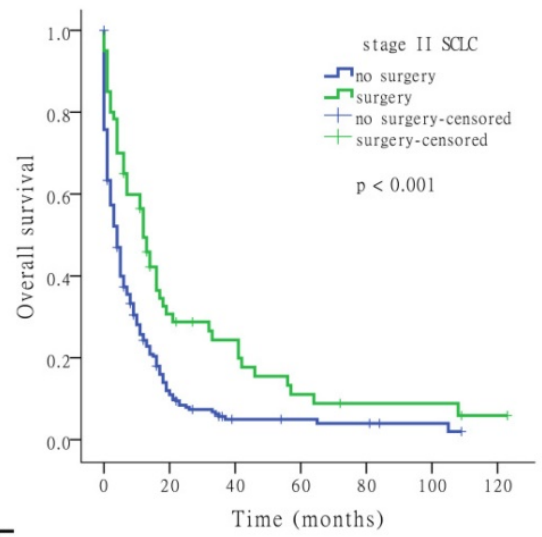

F

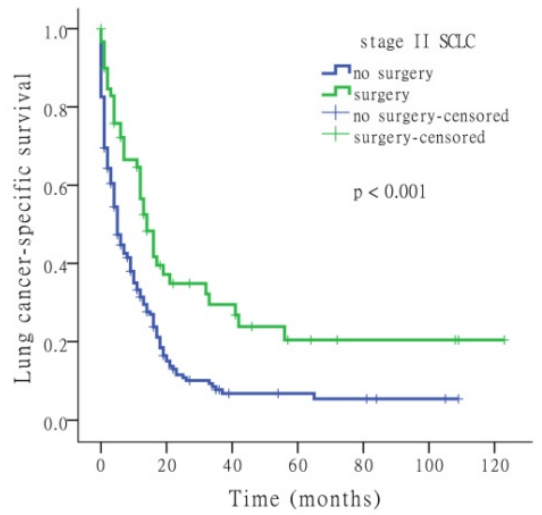

C

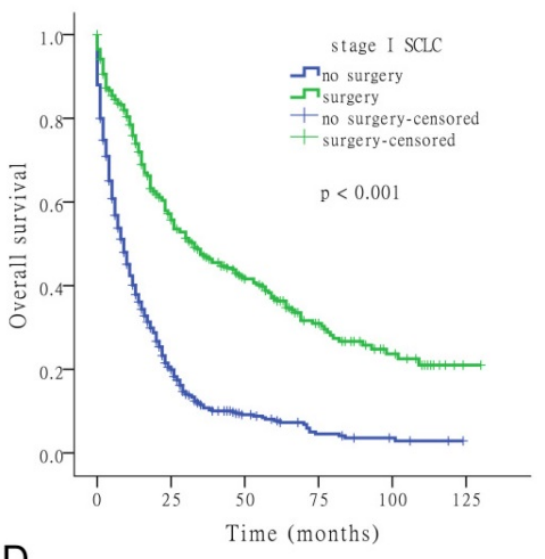

D

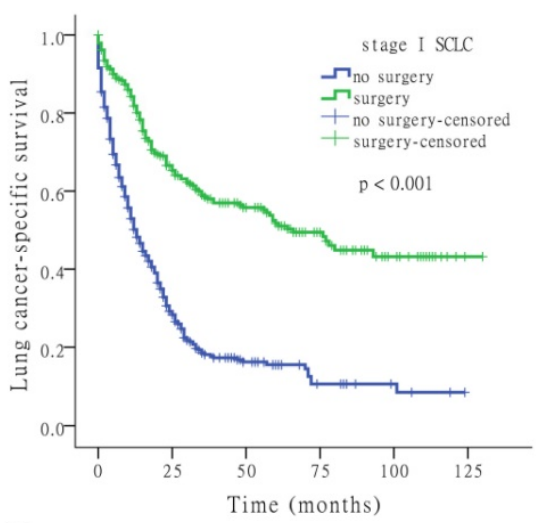

G

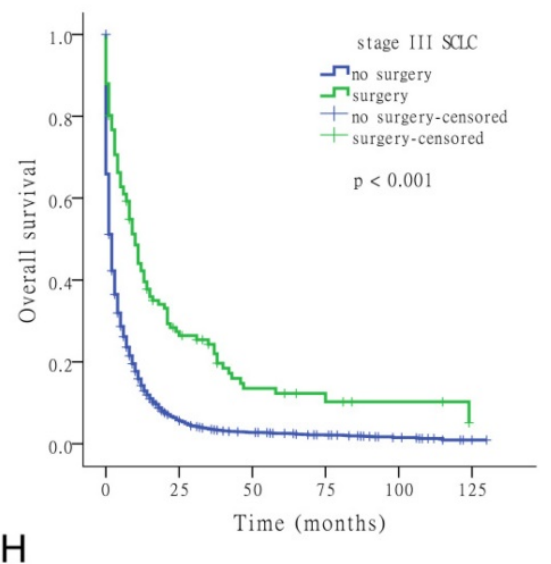

$\mathrm{H}$

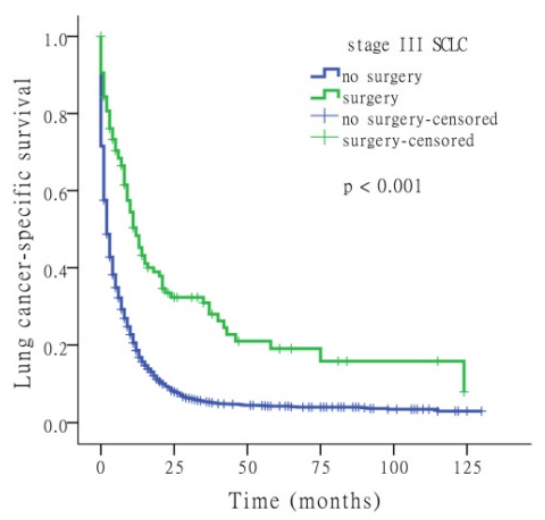

Fig. 1: Kaplan-Meier survival analysis for OS and LCSS based on surgery or no-surgery at stage I-III and each stage of SCLC. 
A

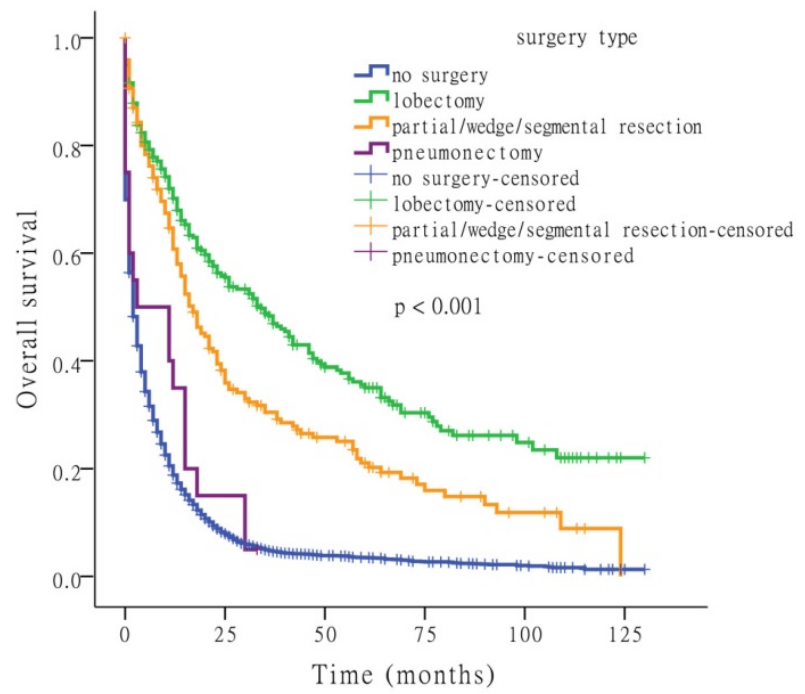

B

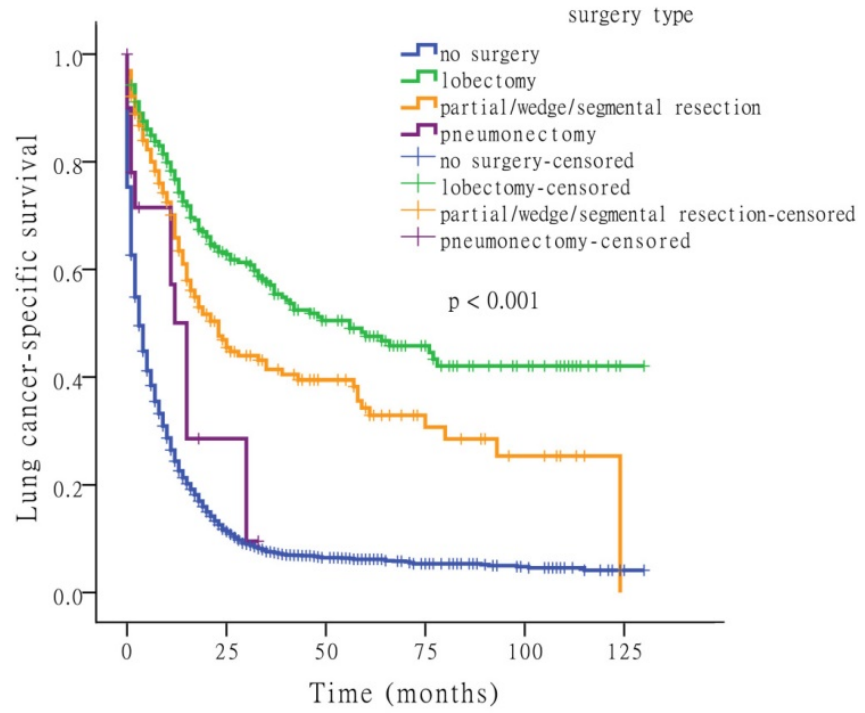

Fig. 2: Kaplan-Meier survival analysis for OS and LCSS based on surgery type.

A

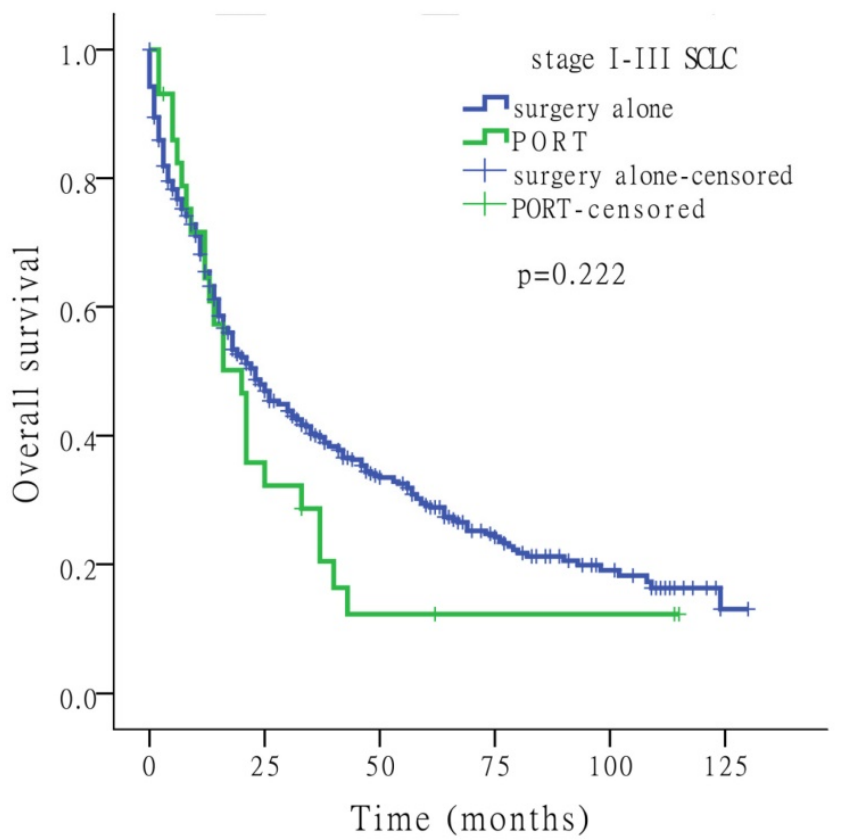

B

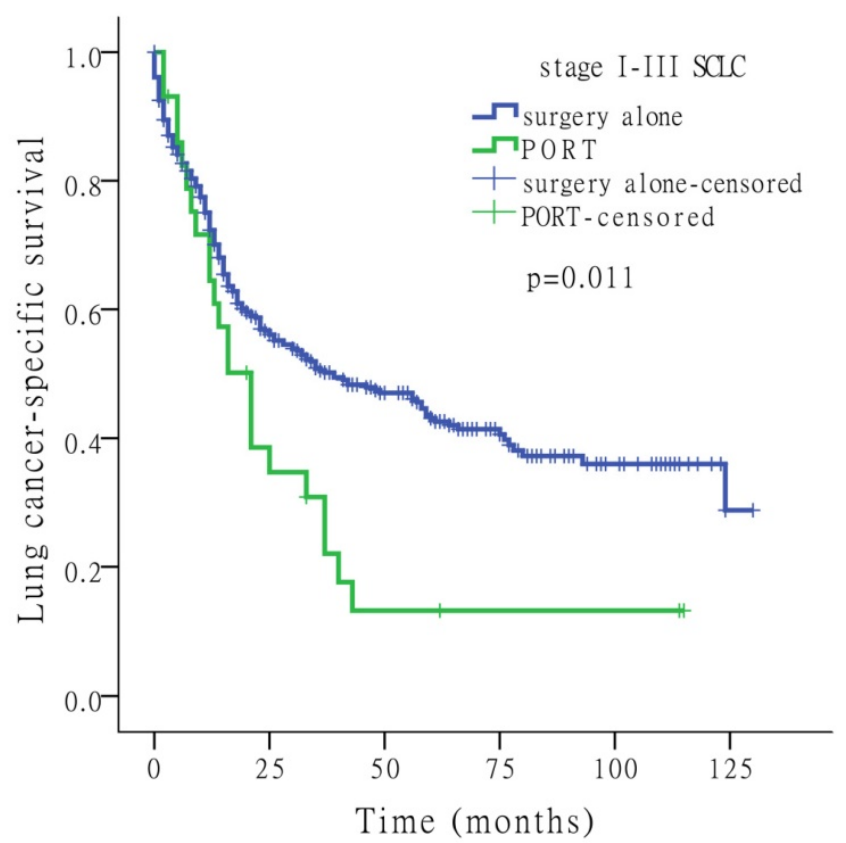

Fig. 3: Kaplan-Meier survival analysis for OS and LCSS to assess the impact of surgery alone or PORT for stage I-III SCLC.

For OS, the median time-to-death (with 95\% confidence interval [CI]) was 2 months $(95 \% \mathrm{CI}$ : 1.8-2.2 months) for no-surgery, 34 months (95\% CI: 25.1-42.9 months) for lobectomy, 17 months (95\% CI: 13.1-20.9 months) for partial/wedge/segmental resection, and 3 months (95\% CI: 0.0-16.1 months) for pneumonectomy. For LCSS, the median time-to-death was 3 months (95\% CI: 2.7-3.3 months) for no-surgery, 56 months for lobectomy $(95 \%$ CI: 31.5-80.5 months), and 23 months (95\% CI: 16.3-29.7 months) for partial/wedge/segmental resection, and 15 months (95\% CI: 11.7-18.3 months) for pneumonectomy.

\section{Effects of PORT on survival}

Of the 4,780 patients included in the study, 92 $(1.9 \%)$ underwent PORT. Fig. 3 shows the Kaplan-Meier survival analysis for OS and LCSS based on surgery alone and PORT with stage I-III SCLC. PORT did not significantly improve survival compared to surgery alone in patients with SCLC (Tables 2-4).

\section{Multivariate analysis of survival}

Table 5 shows the multivariate Cox analysis for OS and LCSS in stages I to III SCLC. Increased age ( $\geq$ 
65 years) and diagnosis at stages II or III were both significant risk factors for SCLC (HRs $>1$, all $p<$ $0.001)$. Surgical resection was associated with a favorable prognosis for SCLC (HRs $<1, p<0.001$ ). Gender and race were not prognostic factors for SCLC (all $p>0.05$ ).

Table 5. Multivariate Analysis for Small Cell Lung Cancer Using Cox Proportional Hazards Model $(n=4,780)$

\begin{tabular}{lllll}
\hline Variable & QS & \multicolumn{2}{l}{ LCSS } & \\
\hline & HR $(95 \%$ CI $)$ & P value & HR $(95 \%$ CI $)$ & P value \\
\hline $\begin{array}{l}\text { Age, years } \\
<65\end{array}$ & & & & \\
$\geq 65$ & $1.392(1.292-1.500)$ & $<0.001$ & $1.356(1.251-1.470)$ & $<0.001$ \\
Gender & & & & \\
Female & & & & 0.263 \\
Male & $1.058(0.996-1.124)$ & 0.065 & $1.039(0.972-1.110)$ & \\
Race & & & & 0.080 \\
White & & & & 0.150 \\
Black & $0.935(0.842-1.038)$ & 0.207 & $0.901(0.802-1.013)$ & \\
$\begin{array}{l}\text { Other } \\
\text { Surgery }\end{array}$ & $0.897(0.769-1.046)$ & 0.165 & $0.883(0.746-1.046)$ & \\
No & & & & $<0.001$ \\
Yes & $0.463(0.411-0.521)$ & $<0.001$ & $0.429(0.374-0.492)$ & \\
TNM stage & & & & $<0.001$ \\
$\begin{array}{l}\text { Stage I } \\
\text { Stage II }\end{array}$ & $1.593(1.383-1.834)$ & $<0.001$ & $1.781(1.521-2.086)$ & \\
Stage III & $1.986(1.824-2.164)$ & $<0.001$ & $2.308(2.093-2.545)$ & $<0.001$ \\
\hline
\end{tabular}

\section{Discussion}

Recently published retrospective studies have reported favorable outcomes for surgery in stage I and II SCLC patients [29, 30]. However, whether surgical resection is beneficial for stage III SCLC patients remains unclear, which we aimed to address in this report. In this study of a large national database, patients with stage I-III SCLC who underwent lung resection had significantly better survival than patients treated without surgical resection. This benefit was particularly noted in patients with stage I disease. Patients who underwent lobectomy had the best outcomes with a median OS of 34 months and LCSS of 56 months compared to 2 months OS and 3 months LCSS for non-surgically treated patients. Further analysis revealed that surgically treated patients who underwent PORT did not have a higher OS and LCSS than those who underwent surgery alone.

Our research has provided novel findings and approaches compared to previous publications. First, we studied patients with stages I to III SCLC who underwent surgical resection. Currently, patients with stage I SCLC are offered surgery as part of their treatment plan, whereas those with stage II or stage III disease undergo chemoradiotherapy [31]. Yu et al. [30] reported a favorable 5-year survival rate of $34.3 \%$ in patients with stage I SCLC underwent surgical resection. Rostad et al. [32] showed that the 5-year survival in the surgical group was $44.9 \%$ compared to $11.3 \%$ in the conventionally treated group in patients with stage I disease. We found that not only stages I and II, but also stage III SCLC patients who underwent surgery had favorable outcomes. Thus, surgery may play a greater role than current guidelines suggest. Second, because chemotherapy has become the mainstay of treatment for SCLC, many studies have focused on surgery with systemic chemotherapy $[33,34]$. We chose patients who did not undergo chemotherapy, to determine the effects of surgery on survival. Finally, we included a large group of patients who had been diagnosed with SCLC from the SEER database in recent years, which made the study results more credible. The current standard of care for patients with SCLC is chemotherapy and radiotherapy. The value of surgery remains controversial, but recent recommendations have suggested that surgical resection may be an option for early-stage disease [27, 28]. A recently published retrospective study by Schreiber et al. [29] analyzed the role of surgery in over 14,000 patients with limited-stage SCLC diagnosed between 1998 and 2002, based on the SEER registry. The authors observed that surgery significantly improved survival outcomes compared to non-surgically treated patients, with a median survival of 42 months versus 15 months $(p<0.01)$ for patients with local disease, and 22 months versus 12 months $(p<0.001)$ for those with regional disease. Furthermore, surgically treated patients had a 5-year OS rate of $34.6 \%$ compared to $9.9 \%$ for the non-surgery group. Subgroup analysis further revealed that in comparing surgical resection with non-surgery groups, the 5-year OS rate was $44.8 \%$ versus $13.7 \%(p<0.001)$ for stage I patients and $26.3 \%$ versus $9.3 \%(p<0.001)$ for those with regional disease. Moreover, in comparing the type of surgeries, patients who underwent lobectomy had the most favorable outcomes, with 52.6\% 5-year OS rates for local disease and $31.8 \%$ for regional disease. Another SEER-based retrospective study of 1,500 stage I patients treated between 1998 and 2004 found that patients who underwent lobectomy regardless of radiotherapy had a 5-year OS of 50\% [30]. Patients who underwent lobectomy without adjuvant radiotherapy had a $49.1 \%$ 5-year OS and those who had combined lobectomy and radiotherapy had a 5 -year OS of $57.1 \%$ compared to $28.4 \%$ 5-year OS of those who underwent radiotherapy alone. Our findings are in agreement with these retrospective studies. However, our data showed that at each stage of disease, PORT could not improve survival compared to surgery alone. This finding may be because the number of PORT patients was few. Thus, large-scale investigations on PORT patients are 
needed.

This retrospective report had some limitations. First, the chemotherapy information was incomplete and not explicit. We chose patients who had not undergone chemotherapy treatments, but some of these patients could not be determined. Second, as a retrospective study, inherent selection bias was inevitable. Third, we found that PORT represented patients who underwent surgery including surgery to other regional or distant sites.

Insights into the potential cellular and molecular mechanisms need to be investigated in more detail. Gazdar and co-workers [35] showed that the biological characteristics of SCLC partially explained the high rate of treatment failure. Inactivation of the tumor suppressor genes TP53 and RB1 is probably the initiating molecular event. Further, frequent disruption of several signaling networks, including Notch signaling, likely also plays a role. NFIB encodes a transcriptional regulator that is essential for embryonic lung and brain development. It is often overexpressed in metastases and is important for the progression and invasion of tumors [36, 37]. These characteristics partly explain the rapid growth and early metastatic spread of SCLC. This is why patients with very early-stage disease can undergo surgical resection, and surgery usually needs to be carefully considered for patients with stage III SCLC. Our study demonstrated that patients with stage I-III SCLC who underwent surgical resection had significantly better survival.

\section{Conclusions}

Patients with stage I-III SCLC appear to benefit from surgical resection. Thus, surgical therapy should not be withheld when a solitary pulmonary nodule is found to be SCLC. In patients who can tolerate lobectomy, we suggest that this should be the operation of choice. However, in patients who cannot tolerate a lobectomy, a lung-sparing procedure, such as wedge resection, also appears to offer survival benefit. Although not studied in this report, chemotherapy is an important component in the treatment of SCLC, and should be considered for all patients. PORT did not improve survival compared to treatment with surgery alone in patients with stages I to III SCLC. This study expands upon other studies that suggest that oncologists should consider offering surgical therapy to patients with stage I-III SCLC.

\section{Abbreviations}

HR: hazard ratio; LCSS: lung cancer-specific survival; OS: overall survival; PORT: postoperative radiotherapy; SCLC: small-cell lung cancer; SEER: Surveillance, Epidemiology, and End Results.

\section{Acknowledgement}

The work was supported by Key Research and Development Plan of Shandong Province [grant numbers 2015GSF118109, 2015GSF118063], National Science Foundation of China [grant number 81672288] and Medicine and Health Development Plan of Shandong Province [grant number 2016WS0433].

\section{Competing Interests}

The authors have declared that no competing interest exists.

\section{References}

1. Siegel RL, Miller KD, Jemal A. Cancer statistics, 2016. CA: a cancer journal for clinicians. 2016; 66: 7-30.

2. Torre LA, Siegel RL, Jemal A. Lung Cancer Statistics. Advances in experimental medicine and biology. 2016; 893: 1-19.

3. Conen K, Hagmann R, Hess V, Zippelius A, Rothschild SI. Incidence and predictors of Bone Metastases (BM) and Skeletal-Related Events (SREs) in Small Cell Lung Cancer (SCLC): A Swiss patient cohort. Journal of Cancer. 2016; 7: 2110-6.

4. Mountain CF. The international system for staging lung cancer. Seminars in surgical oncology. 2000; 18: 106-15.

5. Ganti AK, Zhen W, Kessinger A. Limited-stage small-cell lung cancer: therapeutic options. Oncology (Williston Park, NY). 2007; 21: 303-12; discussion 12, 15-8, 23.

6. Jhun BW, Lee KJ, Jeon K, Suh GY, Chung MP, Kim H, et al. Clinical applicability of staging small cell lung cancer according to the seventh edition of the TNM staging system. Lung Cancer. 2013; 81: 65-70.

7. Govindan R, Page N, Morgensztern D, Read W, Tierney R, Vlahiotis A, et al. Changing epidemiology of small-cell lung cancer in the United States over the last 30 years: analysis of the surveillance, epidemiologic, and end results database. Journal of clinical oncology : official journal of the American Society of Clinical Oncology. 2006; 24: 4539-44.

8. Hann CL, Rudin CM. Management of small-cell lung cancer: incremental changes but hope for the future. Oncology (Williston Park, NY). 2008; 22: 1486-92.

9. Qiu YF, Liu ZG, Yang WJ, Zhao Y, Tang J, Tang WZ, et al. Research progress in the treatment of small cell lung cancer. Journal of Cancer. 2017; 8: 29-38.

10. Fox W, Scadding JG. Medical Research Council comparative trial of surgery and radiotherapy for primary treatment of small-celled or oat-celled carcinoma of bronchus. Ten-year follow-up. Lancet (London, England). 1973; 2: 63-5.

11. Lad T, Piantadosi S, Thomas P, Payne D, Ruckdeschel J, Giaccone G. A prospective randomized trial to determine the benefit of surgical resection of residual disease following response of small cell lung cancer to combination chemotherapy. Chest. 1994; 106: 320S-3S.

12. Prasad US, Naylor AR, Walker WS, Lamb D, Cameron EW, Walbaum PR. Long term survival after pulmonary resection for small cell carcinoma of the lung. Thorax. 1989; 44: 784-7.

13. Shields TW, Higgins GA, Jr., Matthews MJ, Keehn RJ. Surgical resection in the management of small cell carcinoma of the lung. The Journal of thoracic and cardiovascular surgery. 1982; 84: 481-8.

14. Shepherd FA, Ginsberg RJ, Patterson GA, Evans WK, Feld R. A prospective study of adjuvant surgical resection after chemotherapy for limited small cell lung cancer. A University of Toronto Lung Oncology Group study. The Journal of thoracic and cardiovascular surgery. 1989; 97: 177-86.

15. Shepherd FA, Ginsberg RJ, Feld R, Evans WK, Johansen E. Surgical treatment for limited small-cell lung cancer. The University of Toronto Lung Oncology Group experience. The Journal of thoracic and cardiovascular surgery. 1991; 101: 385-93.

16. Merkle NM, Mickisch GH, Kayser K, Drings P, Vogt-Moykopf I. Surgical resection and adjuvant chemotherapy for small cell carcinoma. The Thoracic and cardiovascular surgeon. 1986; 34: 39-42.

17. Lucchi M, Mussi A, Chella A, Janni A, Ribechini A, Menconi GF, et al. Surgery in the management of small cell lung cancer. European journal of cardio-thoracic surgery : official journal of the European Association for Cardio-thoracic Surgery. 1997; 12: 689-93.

18. Shepherd FA, Ginsberg RJ, Evans WK, Feld R, Cooper JD, Ilves R, et al. Reduction in local recurrence and improved survival in surgically treated patients with small cell lung cancer. The Journal of thoracic and cardiovascular surgery. 1983; 86: 498-506.

19. Lewinski T, Zulawski M, Turski C, Pietraszek A. Small cell lung cancer I--III A: cytoreductive chemotherapy followed by resection with continuation of chemotherapy. European journal of cardio-thoracic surgery : official journal of the European Association for Cardio-thoracic Surgery. 2001; 20: 391-8. 
20. Hara N, Ichinose Y, Kuda T, Asoh H, Yano T, Kawasaki M, et al. Long-term survivors in resected and nonresected small cell lung cancer. Oncology. 1991; 48: 441-7.

21. Inoue M, Miyoshi S, Yasumitsu T, Mori T, Iuchi K, Maeda H, et al. Surgical results for small cell lung cancer based on the new TNM staging system. Thoracic Surgery Study Group of Osaka University, Osaka, Japan. The Annals of thoracic surgery. 2000; 70: 1615-9.

22. Rea F, Callegaro D, Favaretto A, Loy M, Paccagnella A, Fantoni U, et al. Long term results of surgery and chemotherapy in small cell lung cancer. European journal of cardio-thoracic surgery : official journal of the European Association for Cardio-thoracic Surgery. 1998; 14: 398-402.

23. Eberhardt W, Stamatis G, Stuschke M, Wilke H, Muller MR, Kolks S, et al. Prognostically orientated multimodality treatment including surgery for selected patients of small-cell lung cancer patients stages IB to IIIB: long-term results of a phase II trial. British journal of cancer. 1999; 81: 1206-12.

24. Shepherd FA, Evans WK, Feld R, Young V, Patterson GA, Ginsberg R, et al. Adjuvant chemotherapy following surgical resection for small-cell carcinoma of the lung. Journal of clinical oncology : official journal of the American Society of Clinical Oncology. 1988; 6: 832-8.

25. Tsuchiya R, Suzuki K, Ichinose Y, Watanabe Y, Yasumitsu T, Ishizuka N, et al. Phase II trial of postoperative adjuvant cisplatin and etoposide in patients with completely resected stage I-IIIa small cell lung cancer: the Japan Clinical Oncology Lung Cancer Study Group Trial (JCOG9101). The Journal of thoracic and cardiovascular surgery. 2005; 129: 977-83.

26. Brock MV, Hooker CM, Syphard JE, Westra W, Xu L, Alberg AJ, et al. Surgical resection of limited disease small cell lung cancer in the new era of platinum chemotherapy: Its time has come. The Journal of thoracic and cardiovascular surgery. 2005; 129: 64-72.

27. Stahel R, Thatcher N, Fruh M, Le Pechoux C, Postmus PE, Sorensen JB, et al. 1st ESMO Consensus Conference in lung cancer; Lugano 2010: small-cell lung cancer. Annals of oncology : official journal of the European Society for Medical Oncology. 2011; 22: 1973-80.

28. Simon GR, Turrisi A. Management of small cell lung cancer: ACCP evidence-based clinical practice guidelines (2nd edition). Chest. 2007; 132: 324S-39S.

29. Schreiber D, Rineer J, Weedon J, Vongtama D, Wortham A, Kim A, et al. Survival outcomes with the use of surgery in limited-stage small cell lung cancer: should its role be re-evaluated? Cancer. 2010; 116: $1350-7$

30. Yu JB, Decker RH, Detterbeck FC, Wilson LD. Surveillance epidemiology and end results evaluation of the role of surgery for stage I small cell lung cancer. Journal of thoracic oncology : official publication of the International Association for the Study of Lung Cancer. 2010; 5: 215-9.

31. Low M, Ben-Or S. Thoracic Surgery in Early-Stage Small Cell Lung Cancer. Thoracic surgery clinics. 2018; 28: 9-14.

32. Rostad H, Naalsund A, Jacobsen R, Strand TE, Scott H, Heyerdahl Strom E, et al. Small cell lung cancer in Norway. Should more patients have been offered surgical therapy? European journal of cardio-thoracic surgery : official journal of the European Association for Cardio-thoracic Surgery. 2004; 26: 782-6.

33. Takei H, Kondo H, Miyaoka E, Asamura H, Yoshino I, Date H, et al. Surgery for small cell lung cancer: a retrospective analysis of 243 patients from Japanese Lung Cancer Registry in 2004. Journal of thoracic oncology : official publication of the International Association for the Study of Lung Cancer. 2014; 9: 1140-5.

34. Granetzny A, Boseila A, Wagner W, Krukemeyer G, Vogt U, Hecker E, et al. Surgery in the tri-modality treatment of small cell lung cancer. Stage-dependent survival. European journal of cardio-thoracic surgery : official journal of the European Association for Cardio-thoracic Surgery. 2006; 30: 212-6.

35. Takebe N, Miele L, Harris PJ, Jeong W, Bando H, Kahn M, et al. Targeting Notch, Hedgehog, and Wnt pathways in cancer stem cells: clinical update. Nature reviews Clinical oncology. 2015; 12: 445-64.

36. Semenova EA, Kwon MC, Monkhorst K, Song JY, Bhaskaran R, Krijgsman O, et al. Transcription Factor NFIB Is a Driver of Small Cell Lung Cancer Progression in Mice and Marks Metastatic Disease in Patients. Cell reports. 2016; 16: 631-43.

37. Wu N, Jia D, Ibrahim AH, Bachurski CJ, Gronostajski RM, MacPherson D. NFIB overexpression cooperates with $\mathrm{Rb} / \mathrm{p} 53$ deletion to promote small cell lung cancer. Oncotarget. 2016; 7: 57514-24. 